\title{
Clearing the Final Hurdle: Getting Students to Engage with Feedback in Higher Education
}

\author{
Peter Wolstencroft ${ }^{1, *}$, and Lean de Main ${ }^{2}$ \\ ${ }^{1}$ Liverpool Business School, Liverpool John Moores University, Liverpool, UK \\ ${ }^{2}$ Faculty of Business and Law, De Montfort University, Leicester, UK
}

\begin{abstract}
Higher Education within the UK over the last fifty years has increasingly been defined by the end product and this means that both students and lecturers tend to focus on the outcome rather than the process. For many students this means that assessments are seen as barriers to their final grade, rather than as a support to help them reflect on their performance. The purpose of this paper is to explore how students can become more engaged with the comments made on assessments. It concludes by suggesting that whilst audio feedback has proved to be successful in this respect, video feedback might well be an even better way of encouraging students to listen to what they are being told and then improve subsequent work.
\end{abstract}

\section{Introduction}

Defining the purpose of education has always been a matter of much debate. In the last fifty years in the UK, this debate has been amplified by two key events; firstly a speech in 1976 at Ruskin College by the then Prime Minister, James Callaghan, that explicitly linked education to the needs of industry [1] and secondly the passing of the 1992 Further and Higher Education Act [2] which sought to enhance education with best practice from the private sector, a process underpinned by the view that 'If you can't measure it, you can't improve it'. Whilst the presupposition that by introducing ideas from the private sector you will make education 'better' in some ways might well be viewed as fundamentally flawed [3], that has not stopped it becoming deeply rooted in the current system. This approach which stresses measurement at all stages, was described by Ball [4] as performativity and has become the predominant view of how to describe the quality within a sector that is increasingly defined by its relationship with industry.

The importance of a defined end product that is almost always measured in quantitative terms, has been inculcated into the day-to-day lives of educators. Orr $[5,58]$ talked about how lecturers have learnt to be 'fluent in the language of performativity', in other words, they are aware of the significance of the 'metrics' that are used to describe the quality of the education provided. Measures such as the National Student Survey (NSS), the Postgraduate Teaching Experience Survey (PTES), the Graduate Outcomes Survey as well as a multitude of other quantitative measures such as pass rates and the percentage of students gaining

* Corresponding author: $\underline{\text { P.J.Wolstencroft@ljmu.ac.uk }}$ 
'good' degrees are all used to define quality in UK education. This narrow definition is reinforced by the Office for Students (known as the OfS), the independent regulator of Higher Education in the UK, who list a variety of criteria they use to measure the quality of education, one to note is 'value for money'.

It is not just within the UK that quantitative measures are used to evaluate education. Successive governments in many countries have used exam pass rates to hail the improving quality of education in their countries. Within the last few months, President Macron in France hailed the record $95.1 \%$ of students passing their 'bacc' exams first time as "a triumph" [6], the US High School pass rates have reached a new high of $88 \%$ and in South Africa, the Education Minister hailed the record $81.3 \%$ pass rates as an outstanding achievement. Across the globe, the message is reinforced that the true measurement of success comes in quantitative form, often via the summative assessment at the end of the programme of study.

The focus on summative assessment as the single most prominent measure of success creates a transactional approach to education for many students. Tomlinson [7] discussed the oft-repeated phrase that students are now viewed as customers and although his suggestion that they should actually be viewed as consumers is more in keeping with the heterogenic sector that is education. It does imply an acceptance of the OfS's view that students are paying for a service, hence value for money is paramount and that there should be a defined end product to Higher Education.

The purpose of this paper is to explore ways to help students see assessment as an ongoing process rather than as a series of hurdles to explore how students can become more engaged with the comments made on assessments.

\section{Assessment: a barrier to student's final grade?}

Given the focus on quantitative measures, the implication that education should have a tangible end product and the view that students should be viewed as consumers, it is clear that assessment is something that is inevitably placed at the heart of the education process by both lecturers and students. However, the amount of training these groups have on this process is often minimal. A common complaint amongst lecturers is that students only focus on aspects of the curriculum that they will be assessed on. Ramsden [8] described how students are often focused on the end goal rather than any ongoing process and are liable to ignore anything that they perceive as not being of use in achieving their end goal. Common cries from students are 'will this be in the coursework' or 'tell me what I need to do to pass'. This focus on summative assessment means that individual assignments are perceived to be hurdles to be climbed over, rather than part of an educational journey. Once the hurdle has been cleared, then the danger for both lecturers and students is there will be a shift in focus to the next assessment rather than any reflection on the previous one [9].

For a lecturer this means that engaging students in assessment tends to be problematic. A previous study by the authors found that only a quarter of students at level four access any comments made by lecturers on their submitted work [10], yet almost all will check the overall grade soon after it is released. This lack of engagement with feedback is not limited to any particular group of students, indeed counter intuitively, one of the groups least likely to access comments are those who have recorded the highest grades. This is often linked to students feeling as though they have achieved their immediate goal and so they move on to the next hurdle.

Whilst it is easy to see this problem merely as one where students are not engaging fully with the process, this neglects a number of other factors that need to be taken into account before reaching a conclusion. The quality of many of the comments received by students has been raised as a common concern with too many generic comments being offered under 
the guise of feedback or feedforward [11]. Given the increased numbers attending university in the last two decades, this can partly be ascribed to the pressure lecturers are under to mark the work and return it to students within a short time span, but it might also reflect a number of other factors. The increased use of electronically generated feedback 'quickmarks' has meant that instead of lecturers having to use their own individualised comments, they can assign pre-written comments to the work that they are assessing. In addition, the increased use of rubrics, tables designed to show students exactly why they have been awarded a set mark, have led to a change in the culture for lecturers when marking work. The transparency that is engendered by rubrics means that the repetition of words (so maybe 'good' for those achieving a grade of $60-69 \%$, 'excellent' for $70-79 \%$ ) has led to comments which tend to be judged as generic in nature about the work. It also means that aspirational 'feedforward' comments have focused on why students did not fall into the next category on the rubric. Whilst this would be useful for a repetitious assessment, the nature of university study means that the subsequent assessment is likely to test differing skills.

Given the seemingly intractable problem that we are facing - it is highly unlikely that the importance of final grades will diminish in the near future - the solutions offered require careful implementation. Firstly, it should be noted that student's passivity when it comes to engaging in self-reflection is not something confined to Higher Education, it has been reinforced throughout their prior education through an 'exam factory' approach that stresses the importance of final outcomes [12]. Hence, for lecturers a key aspect is to change the frames of reference of students from seeing assessments as hurdles, to seeing them as being constituent parts of a whole, which flow into each other. This resetting of attitudes towards assessment needs to be embedded from the outset of their studies before patterns are engrained. Arguments for more student co-creation and authenticity in assessment design could be helpful in shifting students' focus from assessment of learning to assessment for learning $[13 ; 14 ; 15]$.

As part of the modification of students' frames of reference, we also need to assess how our messages are delivered. If we accept the premise that the majority of students do not read any written comments given on their work, and that they find both rubrics and a majority of feedback comments unhelpful $[16 ; 17 ; 18]$, then we need to find another medium with which to communicate with students and to engage with them.

\section{Audio feedback: benefits of using}

Audio feedback has been utilised to overcome many of the issues we have identified. A major advantage is that the number of students engaging with the lecturer's comments rises significantly when comments are given in audio rather than written form. Zimbardi et al [19] found that $92 \%$ of first year undergraduates accessed their comments when they were presented in audio format. This represents a significant increase from the research on written comments but clearly, is only part of the story. If students do not find the audio comments useful then the number accessing them is of limited relevance. Thankfully, evidence suggests that audio feedback is seen to be of much greater benefit. Turner and West [20] identified that students found this communication method made feedback far more straightforward to understand. Wolstencroft and de Main [10] concluded that students were far more engaged with their feedback when it was given verbally but they did stress that is was important not to use it in isolation. Students needed to be prepared to receive the comments, otherwise they failed to understand the importance of using comments from each of their assignments in order to help craft future pieces of work.

An additional benefit of using audio feedback is the impact on academics. Most marking software limits lecturers to three minutes of comments and in the previously 
mentioned research, academics reported the time taken in assessing students' work was substantially lower [10]. Despite the reduction in the time taken to complete the comments, the students' perception of the value of the feedback was that it was significantly more useful than the written version. As 'quickmarks' or rubrics are rarely used when given audio feedback, the comments were viewed as being far more individualised. Some students also mentioned that the comments felt far more personal, they could hear their lecturer and they believed that far more time had been taken in the marking which helped them further engage in the process and helped themcomprehend the feedback provided.

\section{Video feedback}

Whilst audio feedback has been used in Higher Education for some time, video feedback is a comparatively recent innovation. Although Brick and Holmes [21] were early pioneers of the method, there is little evidence of it being in widespread use within Higher Education. Early indications suggest it can be of significant benefit to students, as well as being comparatively straightforward for lecturers to implement. Killingback et al [22] identified how using a medium that students were familiar with meant that they were more comfortable in viewing the feedback and also reviewing it, something that the authors noted did not happen with other forms of feedback.

West and Turner's work [20] highlighted the great advantages that video feedback has over its written counterpart. Not only did significant numbers of students prefer receiving it in video form they also felt far more engaged in the process. As with audio feedback, students felt as though there was more of a relationship with the person delivering the comments and as such, they felt far more emotional engagement with the guidance and comments provided. Given that the purpose of this paper is to explore ways to help students see assessment as an ongoing process rather than as a series of hurdles, then getting them engaged in the process, as well as ensuring that they receive high quality feedback from lecturers is clearly of great benefit. Whilst there have been dissenters to this view (for example Mahoney et al [23] stress that even though there are great benefits, in common with many other forms, it is still primarily used to disseminate information rather than to start a dialogue), the prevalent view is that video feedback can encourage students to engage in their assessment feedback as far more access the comments and also believe that what they receive is of high value.

\section{Conclusions}

Returning to the central premise of this paper. The educational environment in which we work is one where the pursuit of quantitative goals has become paramount. Whilst it is not our intention to critique this, indeed we have accepted that this is the case with only minimal comment, our aim is to identify how we can work within this environment to ensure that students are fully engaged in the feedback process.

Given that students have been part of a system that stresses quantitative success from the start, the first conclusion is that it is vital that their frames of reference are changed from an early stage. Whilst the numerical mark given is important, the process of assessment for learning rather than a series of hurdles to overcome needs to be stressed. This is also true for lecturers, many of whom will have been educated in the performative environment that currently exists in Higher Education.

Once students and lecturers have developed further proficiency in the way assessment and feedback can be designed and enhanced, the method of transmission needs to be looked at. Whilst traditional written feedback can be of great benefit if personalised to the learner 
and if the learner engages. Successive pieces of research have identified only a minority of students engage with written feedback and so more innovative methods need to be considered. Audio feedback has many benefits for both lecturers (in terms of reducing marking time) and for students (who perceive it to be of much greater value). It is also the case that it is far more straightforward to personalise the feedback, and hence actively engage students in it, when delivering comments verbally.

Providing video feedback is an emerging area and where used, this has already proved a very good way of engaging learners. Being able to see the person giving you feedback personalises the message even more and students who have received video feedback have tended to play the messages multiple times, suggesting that they are actually engaging in the process and hence, seeing assessment not as singular activities that are designed to be hurdles to clear but instead seeing them as small parts of one big process that is far greater and more complex than merely a numerical value.

\section{References}

1. C. Chitty. Towards a New Education System (Lewes, The Falmer Press. 1989)

2. Department for Education. Further and Higher Education Act (London, HMSO, 1992)

3. C. Thompson, P. Wolstencroft. R. Post-Compulsory Educ., 23 (2), 213-230 (2018). DOI: $10.1080 / 13596748.2018 .1444372$

4. S. Ball. J. Educ. Policy, 18 (2), 215-228 (2003)

5. K. Orr. J. Educ. Teaching, 38 (1), 51-65 (2012)

6. A. Sage. The Times ( $8^{\text {th }}$ July 2020)

7. M. Tomlinson. Brit. J. Sociol. Educ., 38 (4), 450-467 (2017). DOI: 10.1080/01425692.2015.1113856

8. P. Ramsden. Learning to Teach in Higher Education. (2nd ed. Abingdon, Routledge, 2003)

9. M. Price, K. Handley, J. Millar. Stud. High. Educ., 36 (8), 879-896 (2011). DOI:10.1080/03075079.2010.483513

10. P. Wolstencroft, L. de Main. J. Further High. Educ. (2020). DOI: 10.1080/0309877X.2020.1759517

11. D. France, A. Wheeler. Planet, 18 (1), 9-11 (2007). DOI:10.11120/plan.2007.00180009

12. F. Coffield, B. Williamson. From Exam Factories to Communities of Discovery: The democratic route: 38 (Bedford Way Papers, 38) (London, IOE, 2011)

13. N. Meer, A. Chapman. Bus. Manag. Edu. High. Edu. (2015). DOI: 10.11120/bmhe.2014.00008

14. E. Doyle, P. Buckley, J. Whelan. Teach. High. Educ., 24 (6), 739-754 (2019). DOI: 10.1080/13562517.2018.1498077

15. D. Wiliam. Stud. Educ.Eval., 37 (1), 3-14 (2011)

16. K. Chanock. Teach. High. Educ., 5, 95-105 (2000). DOI:10.1080/135625100114984

17. N. Duncan. Assess. Eval. High, Edu., 32, 271-283 (2007)

18. D. Carless. Assess. Eval. High, Edu., 34 (1), $79-89$ (2009). DOI: $10.1080 / 02602930801895786$ 
19. K. Zimbardi, K. Colthorpe, A. Dekker, C. Engstrom, A. Bugarcic, P. Worth, R. Victor, P. Chunduri, L. Lluka, P. Long. Assess. Eval. High, Edu., 42 (4), 625-644 (2016). DOI:10.1080/02602938.2016.1174187

20. J. West, W. Turner. Innov. Educ. Teach. Int., 53 (4), 400-410 (2016). DOI: 10.1080/14703297.2014.1003954

21. B. Brick, J. Holmes. IADIS International Conference on Cognition and Exploratory Learning in the Digital Age, (CELDA, 2008) https://www.researchgate.net/profile/Jasper_Holmes/publication/255585177_Using_sc reen_capture_software for_student feedback_Towards_a methodology/links/5571613 108aedcd33b2938ff/Using-screen-capture-software-for-student-feedback-Towards-amethodology.pdf

22. C. Killingback, O. Ahmed, L. Williams. Nursing Education Today, 72, 32-39 (2019). DOI: $10.1016 /$ j.nedt.2018.10.012

23. P. Mahoney, S. Macfarlane, R. Ajjawi. Teach. High. Educ., 24 (2), 157-179 (2019). DOI: $10.1080 / 13562517.2018 .1471457$ 